\title{
MANAJEMEN PENDIDIKAN
}

\section{TAMAN KANAK-KANAK ISLAM KOTA PADANGSIDIMPUAN}

\author{
ROSMAIMUNA SIREGAR, 2017. Manajemen Pendidikan pada Taman Kanak-kanak Islam
}

Kota Padangsidimpuan ( Perbandingan kurikulum TK Al-Qur'an dengan TK Islam Terpadu)

\begin{abstract}
ABSTRAK
Researchers applying education management especially in the field of curriculum at Kindergarten of Islam in Padang sidimpuan city. Then made a comparison between the application of curriculum management in order to know the similarities and differences between the two models of kindergarten.

To reach the goal, the researcher uses qualitative approach with natural background as the source of data. To collect the necessary data in accordance with the question focus and research objectives, the researcher uses observation, interview and document review techniques. Further data obtained were analyzed by interactive analysis model.

The findings of researchers directly related to the management functions are in each kindergarten. Starting from curriculum planning, pengorgaanisasian, implementation, and supervision of the curriculum. The equation found is mostly in the planning of the curriculum, because each kindergarten has a curriculum planning reference issued by the agency and the depag. Likewise with the supervision of both done by the school as well as the city education office and department of Religious city of Padangsidimpuan. The difference lies in curriculum development, which has directly distinguished the organizing and implementation of the curriculum.

If associated with the opinion of Islamic education management experts then Kindergarten AlQuran is categorized as RA because early childhood education is formally and under the auspices of religious ministries named with RA, while the TK Islam Terpadu and Islamic organizations. Thus the Islamic Kindergarten in the city of Padangsidimpuan must apply the principles of management manipulated by public schools characterized by Islam, because it is under the auspices of the curriculum education office.

This research is practically expected to open a new understanding for the head of kindergarten, especially about urgency of Islamic education management known and applied in every
\end{abstract}


educational activity. So that managed education really applies the principles of education that have been studied and studied by Islamic education management experts.

\section{A. Pendahuluan}

Manajemen pendidikan di tingkat Taman kanak-kanak (TK) saat ini, sudah harus dilaksanakan sesuai dengan konsep-konsep manajemen. Karena pendidikan di tingkat Tk sudah menjadi bagian dalam Sistem Pendidikan Nasional, yakni tepatnya terdapat dalam Bab VI pada pasal 28 SPN No. 20 tahun 2003. Undang - undang ini, merupakan legalitas formal tentang pelaksanaan pendidikan prasekolah.

Adapun bunyi undang-undangnya adalah:

Pendidikan anak usia dini adalah upaya pembinaan yang diajukan kepada anak sejaklahir sampai usia 6 tahun yang dilakukan melalui pemberian rangsangan pendidikan untuk membantu pertumhbuhan dan perkembangan jasmani dan rohani agar anak memiliki kesiapan dalam memasuki pendidikan lebih lanjut.

Bentuk lembaga pendidikan Anak Usia Dini dinyatakan dalam standar nasional pendidikan (SNP), dapat berupa: Taman kanak-kanak (TK), raudatul Atfal (RA), kelompok Bermain (KB), dan tempat Penitip anak (TPA). Adapun TK dan RA merupakan jalur Pendidikan formal. Tk berada di bawah Dinas pendidikan sedangkan RA dibawah pengawasan Departemen Agama.

Jika diperhatikan fakta riil dilapangan, khususnya kota Padangsidimpuan keberadaan TK maupun RA cukup sicnifikan. Sedikitnya, ada 37 TK yang tersebar di 6 kecamatan. Terdiri dari 24 TK,dan 13 RA. Jumlah ini sejalan dengan visi kota Padangsidimpuansebagaikota pendidikan. Jumlah yang cukup banyak ini, harus menjadi dasar piker, agar TK dikelola secara professional dan manajerial yang professional pula.

\section{B. Deskripsi Taman Kanak-Kanak}

Pembicaraan tentang taman kanak-kanak (TK) tidak terlepas dari pembicaraan anak usia dini (PAUD), karena TK merupakan bagian PAUD itu sendiri.Adapun PAUD adalah suatu 
upaya pembinaan yang ditujukan kepada anak sejak lahir sampai dengan usia 6 tahun yang dilakukan melalui pemberian rangsangan pendidikan untuk membantu pertumbuhan dan perkembangan jasmani dan rohani agar anak memiliki kesiapan dalam memasuki pendidikan lebih lanjut, meskipun bukan merupakan persyaratan wajib untuk memasuki pendidikan Dasar (SD).

Menurut Samsudin, Taman Kanak-Kanak adalah lembaga pendidikan prasekolah sebelum memasuki lembaga pendiikan sekolah Dasar yang melibatkan anak didiknya berkisar pada usia 4 s/d 6 tahun, dengan lama pendidikan antara $1 \mathrm{~s} / \mathrm{d} 2$ tahun.

Direktorat Jenderal Manajemen Pendidikan Dasar dan Menengah mendefinisikan Taman Kanak-kanak sebagai salah satu bentuk satuan pendidikan formal yang menyelenggarakan program pendidikan bagi anak usia 4 tahun sampai 6 tahun.

Menurut Carol Seefeldt dan Barbara A. Wasik, istilah Taman Kanak-kanak mewakili pengajaran bagi anak usia lima tahun dan beberapa anak usia empat tahun, tergantung pada usia yang ditetapkan oleh pemerintah untuk masuk sekolah.

Beberapa pendefinian tersebut sejalan dengan apa yang dikemukakan dalam psikologi perkembangan, bahwa masa kanak-kanak awal (3 sampai 6 tahun) untuk mengasah perkembangan kognitifnya maka masuk pre-school adalah hal biasa terlebih lagi Taman kanakkanak.

Berdasarkan beberapa pendapat di atas,maka pembagian kelas pada TK dapat dibagi dua, yaitu sesuaidengan tingkat usia. Diantaranya:

1. TK A rentang usia 4-5 tahun

2. TK B rentang usia 5-6 tahun

C. Landasan Yuridis Taman Kanak Kanak

1. Undang-Undang Dsar Nagara Republik Indonesia Tahun 1945;

2. Undang-undang Nomor 20 tahun 2003 tentang Sistem Pendidikan Nasional; 
3. Undang-undang Nomor 17 tahun 2005 tentang Rencana Pembangunan Jangka Panjang Nasional, beserta segala ketentuan yang dituangkan Rencana Pembangunan Jangka Menengah Nasional;

4. Peraturan Pemerintah Nomor 19 Tahun 2005 tentang Standar Nasional Pendidikan sebagaimana telah diubah dengan peraturan Pemerintah Nomor 32 Tahun 2013 dan perubahan yang kedua dengan Peraturan Pemerintah Nomor 13 tahun 2015;

5. Peraturan Presiden Nomor 60 tentang Pengembangan Anak Usia Dini Holistik-Integratif;

6. Peraturan Menteri Pendidikan dan Kebudayaan Republik Indonesia No 137 tahun 2014 tentang Standar Nasional Pendidikan Anak Usia Dini; dan

7. Peraturan Menteri Pendidikan dan Kebudayaan Republik Indonesia No 146 tahun 2014 tentang Kurikulum 2013 Pendidikan Anak Usia Dini.

\section{Manajemen Perencanaan Kurikulum}

Perancanaan kurikulum adalah perencanaan kesempatan - kesempatan belajar yang dimaksudkan untuk membina siswa kearah perubahan tingkah laku yang diinginkan dan menilai sampai dimana perubahan - perubahan telah terjadi pada diri siswa. Dalam perencanaan kurikulum minimal ada lima hal yang mempengaruhi perencanaan dan pembuatan keputusan yaitu filosofis, konten/materi, manajemen pembelajaran, pelatihan guru dan system pembelajaran.

Tujuan perencanaan kurikulum dikembangkan dalam bentuk kerangka teori dan penelitian terhadap kekuatan social, pengembangan masyarakat, kebutuhan, dan gaya belajar siswa. Beberapa keputusan harus dibuat ketika merencanakan kurikulum dan keputusan tersebut harus mengerah pada spesifikasi berdasarkan criteria. Merencanakan pembelajaran merupakan bagian yang sangat penting dalam perencanaan kurikulum karena pembelajaran mempunyai pengaruh terhadap siswa daripada kurikulum itu sendiri.

Perencanaan kurikulum memiliki beberapa fungsi diantaranya adalah : 
1. Sebagai pedoman atau alat menajemen yang berisi tentang petunjuk dan sumber daya, serta sebagai system control

2. Sebagai roda penggerak organisasi lembaga pendidikan dan tata laksana untuk menciptakan perobahan sesuai dengan tujuan lembaga pendidikan tersebut

3. Sebagai motivasi untuk melaksanakan system pendidikan sehingga mencapai hasil yang optimal

E. Kurikulum TK Al - Qur'an

Sebagaimana dikemukan pada landasan teori yaitu tentang manajemen kurikulum, aktivitas menajemen kurikulum adalah kolaborasi kepala sekolah dengan wakil kepala sekolah, tata usaha, bersama guru - guru melakukan kegiatan manejerial dimaksud agar tujuan institutional pendidikan berlangsung sebagaimana mestinya dan mencapai hasil yang diharapkan. Selanjutnya aktivitas manajemen TK al - qur'an dimaksud mencakup fungsi - fungsi manajemen seperti perencanaan, pengorganisasisan, pelaksanaan, dan pengawasan.

\section{Perencanaan kurikulum TK Al - Qur'an}

Dalam undang - undang system pendidikan nasional terdapat pasal yang mengatur tentang tugas dan kewenangan seorang kepala TK, untuk mengetahui sejauh mana pemahaman para kepala TK Al - Qur'an terhadap undang - undang tersebut penulis memperoleh hasil wawancara sebagai berikut : Pada prinsipnya kewenangan kepala TK Al - qur'an sama dengan tugas dan kewenangan kepala sekolah formal lainnya. Seperti melakukan pengelolaan, pengembangan, pengawasan dan pelayanan teknis untuk menunjang proses pendidikan pada TK Al qur'an. Sebagai kepala TK, disamping sebagai tenaga pendidik juga bertugas merencanakan, melaksanakan proses pembelajaran, menilai hasil pembelajaran dan melakukan bimbingan dan pelatihan.

Selanjutnya kepala TK dalam membuat perencanaan kurikulum bertindak sebagai manager dan bekerjasama dengan guru - guru dan tata usaha. Agar perencanaan tersebut sesuai dengan kebutuhan peserta didik maka setiap kepala TK tentunya mempunyai rujukan dalam menyusun perencanaan kurikulumnya. Kebijakan kepala TK Al - qur'an dalam merancang kurikulum dapat dilihat dari kutipan wawancara berikut : meskipun ada pemisahan antara RA dan TK, hanyalah pemisahan tangggung jawab saja, seperti yang terjadi pada MIN dan SD 
misalnya namun kurikulum yang dipakai tetap sama. Kurikulum yang dipakai yang dipakai adalah standar kompetensi TK dan RA. Dengan demikian merancang kurikulum TK al - qur'an, kepala TK Bekerjasama dengan para guru serta berpedoman pada kurikulum yang telah ditetapkan tersebut.

F. Manajemen kurikulum TK Islam Terpadu.

Pada dasarnya pertanyaan penelitian yang diajukan terhadap TK Islam Terpadu adalah sama dengan jenis pertanyaan yang dikemukakan pada TK Al qur'an. Baik wawancara tertulis, wawancara langsung, maupun melakukan observasi. Hal ini dilakukan untuk mengetahui dengan jelas persamaan dan perbedaan model kedua TK tersebut. Dengan demikian uraian tentang TK Islam terpadu penulis hanya mencantumkan wawancara tanpa penjelasan seperti apa yang terdapat pada penjelasan TK $\mathrm{Al}$ - qur'an.

\section{Perencanaan Kurikulum TK Islam Terpadu}

Dari hasil wawancara dengan kepala TK Islam Terpadu tentang perencanaan manajemen, terkait dengan tugas dan kewenangan kepala TK menurut Undung-undang Sistem Pendidikan Nasional diperoleh informasi sebagai berikut :

Sesuai dengan ketentuan undang-undang bahwa seorang kepala TK harus memikili beberapa syarat, diantaranya berstatus sebagai guru TK, memiliki kualifikasi akademik, dan kompetensisebagai agen pembelajaran, memiliki pengalaman mengajar minimal 3 tahun di TK, serta memiliki kemampuan untuk memimpin dan kewirausahaan di bidang pendidikan. Syaratsyarat tersebut menegaskan bahwa tugas dan kewenangan kepala TK tidaklah mudah,harus mampu mengelola dan mengembangkan TK, harus juga mengerti administrasi, membuat perencanaanpendidikan, mengatur pelaksanaan program pembelajaran serta melaksanakan evaluasi pada proses pemebelajaran yang dilaksanakan.

Peran kepala TK Islam Terpadu dalam merancang kurikulum dapat dilihat pada kutipan hasil wawancara sebagai berikut:

Dalam Undang-undang Sistem Pendidikan Nasional tentang Pendidikan Anak Usia Dini, terdapat dua bentuk lembaga formalnya yaitu TK dengan RA, dalam prakteknya bagi yang melaporkan PAUD nya pada dinas pendidikan maka dikategorikan sebagai TK, sedangkan yang 
berada di bawah naungan departemen agama dinamakan dengan RA. TK Islam Terpadu sendidir berada di bawah naungan dinas pendidikan. Namun demikian, semua TK dan RA memperoleh panduan kurikulum yang sama-sama dikeluarkan dinas pendidikan dan depag yaitu panduan kurikulum untuk TK dan RA tahun 2004. Masing-masing kepala TK diharuskan berpedoman pada panduan tersebut namun diberi kewenangan untuk mengembangkan kurikulum sesuai dengan visis dan misi TK yang dikelolanya. Bahan, memilih strategi atau metode

Hasil wawancara tentang identifikasi bahan, memilih strategi atau metode pembelajaran dalam merancang kurikulum, diperoleh informasi sebagai berikut:

Sesuai dengan misi TK Islam Terpadu sendiri yaitu menyelenggarakan system pembelajaran yang islami, aktif, kreatif, efektif, dan menyenangkan. Saya selaku kepala TK berusaha mengidentifikasi, menetapkan bahan,memilih strategi dan metodepembelajaran yang dapt mengintegrasikan nilai-nilai islam pada setiap pembelajaranna.

Tentang rencana pemebelajaran di TK, seperti menyusun kalender pendidikan, program harian, mingguan, bulanan,caturwulan, semester, dan prota (program tahunan), penelitiperoleh dari beberapa dokumen TK Islam Terpadu.

Prinsip-prinsip pembelajaran seeprti, belajar sambil bermain dan sebaliknya, dapat penelititemukan di TK Islam Terpadu. Hal ini dapat dibuktikan ketika peneliti barada di TK IT Al-Kaustar untuk melihat secara langsung kegiatan pada hari itu. Dimana pada hari tersebut anak-anak tidak berada dalam kelas akan tetapi berada di tempat bermain sambil dibimbing oleh guru berlomba memakai sepatu, tema pada hari itu adalah aktivitasku.

Pembelajaran berorientasi pada perkembangan dan kebutuhan anak serta menggunakan pendekatan tematik, prinsip pembelajaran seperti ini juga diperoleh dari hasil wawancara dengan kepala TK Islam Terpadu sebagai berikut:

Pembelajaran yang dirancang oleh kepala TK selalu disesuaikan dengan perkembangan anak, tidak memaksakan pembelajaran yang tidak sesuai dengan traf kemampuannya. Yang paling diutamakan adalah sosialisasi dengan teman,orang di sekitarnya serta lingkungan, sehingga jika seorang anak sudah merasa sesuai maka pembelajaran pun akan mudah kita terapkan sesuai dengan tahapan perkembangannya. 
Tentang pendekatan tematik juga diperolehinformasi kepala TK Islam terpadu sebagai berikut:

Dalam rencana pembelajaran di TK Islam Terpadu ini disusun berdasarkan tema, misalnya tema tentang diri sendi,lingkunganku, ruang tamu, rumah sakit, kepolisisan, dan lain-lain. Jika temanya membutuhkan pengalaman langsung maka, pihak sekolah akan mengajak peserta didik langsung ke objek tema yang dimaksud.

Kegiatan pembelajaran yang aktif, kreatif, dan menyenangkan juga merupakan prinsipprinsip pembelajaran yang ada pada TK Islam Terpadu. Untuk menemukan informasi ini peneliti melakukan pengamatan langsung di TK IT tersbut. DI sela-sela jam istiirahat,yaitu ketika sedang makan bersama. Guru-guru senantiasa mengayomi anak-anak dan memberi teguran lewat nyanyian, atau gurauan agar anak tidak merasa sedang dimarahi. Misalnya lagi jika ada anak yang suka menjahili temannya, maka akan dinyanyikan barsama lagu tentang hadis orang yang saling menyayangi, sehingga anak langsung bersalaman dan bermaafan.

Seperti yang dikemukakan pada TK Al-Qur'an, agar sampai pada maksud dan tujuan penelitian yaitu tentang out put TK IT, peneliti juga menanyakan tentang rencana pembelajaran (RP) khususnya pelajaran, khususnya pelajaran baca al-qur'an dan yang menjadi pelajaran unggulan pada TK IT, yaitu rincian pelajaran untuk satu kali tatapmuka. Kemudian yang terpenting dari RP ini juga adalah merancang catatan kemajuan siswa setelah mengikuti pelajaran. Hasil wawancara diperoleh sebagai berikut:

Sesuai dengan jadwal pelajaran yang ditetapkan, pelajaran iqra' memang diberikan setiap hari, namun bukan merupakan pelajaran yang harus diburu, perkembangannya disesuaikan dengan kemampuan anak. Karena target yang diharapkan anak bukan hanya mampu membaca al-qur'an tapi juga terampil dalam berbagai hal, baik mengasah kecerdasannya, sosialisasinya, dan perkembnagn psikomotoriknya, serta anak dibiasakan dengan suasana islami, ini yang terpenting dalam setiap pembelajaran di TK IT.

Untuk mendukung hasil wawancara di atas, pada saat itu juga guru TK tersebut langsung memperlihatkan buku penghubung orangtua dan guru, dimana buku ini berisis tentang jadwal pelajaran mulai dari senin-sabtu, dan pesan-pesan yang hendak disampaikan oleh guru kepada orangtua atau sebaliknya. 
Rencana Program Pembelajaran (RPP)juga merupakan kegiatan yang ada dalam perencanaan kurikulum. Dalam kegiatan ini kepala sekolah dengan para guru bekerja sama membuat rincian pembelajaran untuk satu kali tatap muka, catatan kemajuan ini dinamakan buku penghubung.

G. Persamaan dan perbedaan manajemen perencanaan kurikulum TK Al-Qur'an dengan TK Islam Terpadu

Pada dasarnya, persamaan dan perbedaan sudah sangat jelas terdapat pad kedua model TK tersebut. Persamaan itu dikarenakan karena kedua jenis TK sama-sama TK Islam yang bertujuan menerapkan nilai-nilai Islam pada pendidikan usia dini. Sedangkan perbedaannya terletak pada pengembangan kurikulumnya saja. Namun yang menjadi harapan dalam hasil penelitiannya adalah menggambarkan adanaya penerapan manajemen dalam kurikulum kedua jenis TK tersebut. Dengan demikian akan diuraikan persamaan dan perbedaan manajemen kurikulumnya sebagai berikut:

a. Fungsi-fungsi manajemen seperti perencanaan kurikulum, masing-masing terdapat pada kedua model TK tersebut.

b. Dalam merencanakan kurikulum antara TK Al-Qur'an dengan TK-IT sama-sama memiliki panduan kurikulum yang dikeluarkan oleh dinas pendidikan Departemen Agama yakni kurikulum 2004, Standar Kompetensi TK dan RA.

c. Sama-sama mengembangkan kurikulum yang dikeluarkan dinas dan depag yang menjadi kekhasan darimasing-masing TK.

d. Sama-sama memiliki bahan, strategi, dan metode khusus dalam merancang kurikulum yang berkitan dengan pembelajaran al-qur'an yakni metode iqra'.

H. Perbedaan Manajemen Perencanaan Kurikulum TK Al-Qur'an dengan TK Islam Terpadu

a. Pengembangan kurikulum TK Al-Qur'an lebih mengutamakan kemampuan membaca alQur'an sehingga out put yang diharapkan dalam satu tahun ajaran, anak mampu membaca alQur'an . sedangkan TK IT pengembangan kurikulum lebih mengutamakan kemampuan anak dalam mengintegrasikan nilai-nilai islam terhadap kemampuan anak sehingga out put yang 
diharapkan bukan hanya mampu membaca al-qur'an tetapi juga mampu mengasah kecerdasan spiritual anak sejak dini.

b. TK Al-Qur'an berada di bawah naungan depag dan dapatmenggunakan penamaan TK AlQur'an atau RA Al-Qur'an.Adapun TK IT di baawah pengawasan dinas pendidikan serta berada di bawah naungan Jaringan Sekolah Islam Terpadu.

c. Terdapat perbedaan dalam menetapkan rencana pembelajaran di TK, di TK Al-Qur'an tidak terdapat kalender pendidikan, program mingguan, bulanan, sedangkan di tk it rencana pembelajaran tersebut sangat lengkap, mulai dari kalender pendidikan, program harian, mingguan, bulanan, semesteran, bahkan prota.

\section{DAFTAR PUSTAKA}

Arikunto, Suharsimi, Evaluasi Program Pendidikan; Pedoman Teoritis Praktis Bagi Praktisi Pendidikan, Jakarta: Bumi Aksara, 2004.

Departemen Pendidikan Nasional, Standar Nasional Pendidikan dan Peraturan Pemerintah Nomor 19 Tahun 2005, Jakarta: Sinar Grafika, 2005.

------,Undang-undang Repulik Indonesia No 20 Tahun 2003 tentang Sistem Pendidikan Nasional (Sisdiknas), Jakarta: Sinar Grafika, 2003.

Mastuhu,Memberdayakan Sistem Pendidikan Islam, Jakarta: Logos,1999.

Moleong, L. J, Metode Penelitian Kualitatif,Bandung: Remaja Rosdakarya, 2006.

Sondang P. Siagian, Manajemen Sumber Daya Manusia, Jakarta: Bumi Aksara, 2006.

Syafaruddin, Manajemen Lembaga Pendidikan Islam, Jakarta: Ciputat Press, 2005. 